\title{
A MAGISTRATURA CRIMINAL COMO A ÚLTIMA FRONTEIRA DA CIDADANIA
}

\section{CRIMINAL MAGISTRATE AS THE LAST FRONTIER OF CITIZENSHIP}

\author{
Ana Carolina Couto Matheus*
}

\begin{abstract}
RESUMO
O acusado da prática de um crime tem direito de ser julgado por uma pessoa que acredite na possibilidade de sua inocência. Consciente do seu papel, alicerçado na dignidade da pessoa humana, atento aos direitos decorrentes da cidadania e realizando o que prega o princípio da sustentabilidade social, o juiz de uma vara criminal deve atuar pensando na construção de uma sociedade mais justa, visando a erradicação da marginalização e redução da desigualdade, sem preconceitos e evitando qualquer forma de discriminação.
\end{abstract}

Palavras-chave: Dignidade da pessoa humana. Sustentabilidade social. Juiz criminal.

\begin{abstract}
The accused of a crime has the right to be tried by a person who believes in the possibility of his innocence. Conscious of its role, based on the dignity of the human person, aware of the rights deriving from citizenship and realizing what he preaches the principle of social sustainability, the judge of a criminal court must act thinking of building a more just society , for the elimination of marginalization and inequality reduction, unprejudiced and avoiding any form of discrimination.
\end{abstract}

Keywords: Human dignity. Sustainability social. Criminal judge.

\section{INTRODUÇÃO}

O objeto deste trabalho é refletir sobre o direito das pessoas acusadas de terem praticado condutas que se enquadram como crimes, analisando a potencialidade de equívoco cometido pelo sistema com reflexo na atuação do Poder Judiciário no momento de intervir nas relações jurídicas do Estado frente aos acusados.

O objetivo deste trabalho é destacar a Magistratura criminal como a última fronteira da cidadania, provocando os operadores do direito a fazerem uma avaliação acerca do sistema criminal.

A pesquisa em testilha analisa, à luz da teoria principiológica constitucional, com foco nas garantias e direitos fundamentais, os reflexos da interpretação judicial e das manifestações doutrinárias considerando o contexto normativo no qual se insere o Direito em confronto com a realidade de um juiz criminal.

Artigo submetido em 09 de julho de 2021 e aprovado em 15 de setembro de 2021.

* Doutora em Ciência Jurídica pela UNIVALI-SC. Mestre em Direito pela UNIPAR-PR. Especialista em Direito Tributário pela UnP-RN. Pós-Graduada em Direito Constitucional pela UVB-SP. Graduada em Direito pela TOLEDO-SP. Professora Adjunta IV do CCJSA da Ufac-AC. Coordenadora do Núcleo de Prática Jurídica e Estágios do Curso de Direito da Ufac. Coordenadora e Professora do Curso de Pós-Graduação do CCJSA da Ufac. Orientadora. Conferencista. Conselheira Editorial. Pesquisadora. Advogada. Consultora Jurídica. E-mail: ana.matheus@ufac.br. 
Para tanto, ressalta aspectos nem sempre populares, mas necessários à realização de uma boa prestação Jurisdicional, como a expectativa da comunidade diante da atuação de um juiz criminal, a observação da experiência da vítima de crimes graves, a divergência na versão dos acusados com os policiais, a orientação dos tribunais e da doutrina, a superficialidade nas avaliações resultando na avaliação singela para a responsabilização.

A pesquisa em tela busca destacar o debate, sob a ótica do que vem sendo relegado a segundo plano. As consequências desta relação são nefastas para o Jurisdicionado, para o Julgador e até mesmo para o sistema.

\title{
2 A SUSTENTABILIDADE SOCIAL COMO CONCRETIZAÇÃO DA DIGNIDADE DA PESSOA HUMANA
}

A sustentabilidade se apresenta como uma nova opção na busca de uma sociedade mais justa. Propõe uma quebra no paradigma consumista que está levando o Planeta à exaustão, propondo mudança na forma de vida em busca, não somente da manutenção na vida terrestre, mas na busca de uma vida mais digna. "O paradigma da sustentabilidade consiste na busca de uma sociedade global capaz de se perpetuar indefinidamente no tempo em condições de dignidade" ${ }^{1}$ (REAL FERRER, 2012, p. 319, tradução nossa).

Dentre outras classificações, a doutrina apresenta a sustentabilidade nas dimensões ambiental, econômica, tecnológica e social, cada qual com seu enfoque específico, mas todas com base no mesmo pressuposto: a manutenção da vida terrestre, com mais dignidade. A sustentabilidade é reconhecida como um princípio de natureza horizontal, aplicável em várias áreas do conhecimento, notadamente na ciência jurídica, a indicar sua aplicação com amplitude no direito.

O que mais interessa a este estudo é a vertente social da sustentabilidade, que objetiva a construção de uma sociedade equilibrada, inclusiva e sempre em busca de acabar com qualquer tipo de discriminação. Na concepção de Real Ferrer:

\begin{abstract}
O espectro da sustentabilidade social é tão amplo quanto a atividade humana, pois se trata de construir uma sociedade mais harmoniosa e integrada, para que nada de humano escape a esse objetivo. Da proteção da diversidade cultural à garantia real do exercício dos direitos humanos, ao fim de qualquer tipo de discriminação ou acesso à educação, tudo se enquadra nesta rubrica. ${ }^{2}$ (REAL FERRER, 2012, p. 322, tradução nossa).
\end{abstract}

A sustentabilidade social encontra guarida na dignidade da pessoa humana, que é um dos fundamentos da República Federativa do Brasil (CRF/88, art. $1^{\circ}$, inciso III).

Em verdade, a dignidade da pessoa humana está em posição superior aos princípios, posto que é um fundamento, termo que engloba um conjunto de princípios. Em outras palavras, do fundamento que orienta a dignidade da pessoa humana decorrem vários princípios e objetivos constitucionais, dentre os quais se destacam uma sociedade justa, a erradicação da marginalização e redução das desigualdades sociais e a promoção do bem de todos sem preconceitos decorrentes de qualquer forma de discriminação.

Aproximando ainda mais para os fins pretendidos neste trabalho, Garcia e Garcia reforçam o argumento afirmando que "esse mínimo existencial há que ser identificado em duas

\footnotetext{
${ }^{1}$ El Paradigma de la sostenibilidad consiste en la búsqueda de uma suciedad global capaz de perpetuarse indefinidade en el tiempo en condiciones de dignidad.

2 El espectro de la sostenibilidad social es tan amplio como la actividad humana, pues de lo que se trata es de construir una sociedad más armónica e integrada, por lo que nada humano escapa a ese objetivo. Desde la protección de la diversidad cultural a la garantía real del ejercicio de los derechos humanos, pasando por acabar con cualquier tipo de discriminación o el acceso a la educación, todo cae bajo esta rúbrica.
} 
dimensões distintas: de um lado, o direito de não ser privado do que se considera essencial à conservação de uma existência minimamente digna; e, de outro, o direito de exigir do Estado prestações que traduzam esse mínimo" (GARCIA; GARCIA, 2015, p. 46). Neste sentido é o entendimento de Magalhães, a saber:

$\mathrm{O}$ art. $1^{\circ}$ da Constituição Federal declara quais são os fundamentos do Estado Democrático de Direito, isto é, aquilo que é o seu alicerce e, portanto, nesse momento começa a materialização do espírito constitucional que os constituintes indicaram no Preâmbulo, pois ganha sua racionalidade, estabelecendo os princípios pelos quais o Estado brasileiro se pautará no seu agir. Entre eles está o princípio da dignidade humana, o mais importante, pois constitui o núcleo de toda a ação estatal, já que o Estado tem como último escopo proporcionar o bem comum, que é a promoção da dignidade humana. (MAGALHÃES, 2012, p. 109).

Essa colocação é importante para o devido enquadramento legal e localização da sustentabilidade social como princípio. A partir de então, é determinante que na apreciação de direitos individuais, seja considerada a sustentabilidade social nas matérias trazidas a conhecimento do julgador.

\section{O EXERCÍCIO DA CIDADANIA}

A construção de um conceito de cidadania não é tarefa singela, pois se apresentam alguns mais restritivo, que se realiza no direito de votar e ser votado, e outros que aquele admitem uma maior amplitude, permitindo, além de participar na construção dos destinos da sociedade, apropriar-se, individualmente, das riquezas coletivas da nação, refletindo diretamente nos direitos sociais previstos no artigo $6^{\circ}$ da Constituição Federal, onde se afirma a educação, a saúde, o trabalho, a moradia, o lazer, a segurança, a previdência social, a proteção à maternidade e à infância, a assistência aos desamparados.

Garcia e Garcia apontam para um mínimo essencial para que se possa concluir a existência de uma vida digna, descrevendo mecanismos para a concretização deste mínimo.

\footnotetext{
Há que se considerar, porém, que um dos poucos consensos teóricos que se tem diz respeito ao valor essencial do ser humano, restando uma pergunta: Será que devemos reduzir o mínimo existencial ao direito de subsistir? (...). Esse mínimo existencial há que ser identificado em duas dimensões distintas: de um lado, o direito de não ser privado do que se considera essencial à conservação de uma existência minimamente digna; e, de outro, o direito de exigir do Estado prestações que traduzam esse mínimo. (GARCIA; GARCIA, 2015, p. 47).
}

Portanto, no conceito de cidadania necessariamente deve ser reconhecido o direito de não ser privado do mínimo que identifica uma vida digna e os mecanismos necessários para exigir do Estado a prestação comprometida.

\section{CONTEXTUALIZANDO O PROBLEMA: A TAREFA DE JULGAR}

Leigos em direito ou com conhecimento pequeno na matéria cometem erro corriqueiro sobre o alcance da palavra jurisdição. Em linguagem vulgar, jurisdição tem um sentido de delimitação territorial, como se quisesse definir um Município, Estado, local em que um profissional exerce seu mister. Todavia, em linguagem formal, a palavra tem origem no latim, formado pelas locuções jures e dicere, com significado "dizer o direito".

Portanto, no campo do direito, somente o magistrado tem a capacidade de dizer quem tem razão, somente ele pode dizer o direito. 


\subsection{A figura do magistrado}

Existe uma frase que acabou entrando no anedotário popular onde-se informa que "Os Juízes pensam que são deuses, os desembargadores têm certeza”. De pronto, forçoso concluir que a brincadeira traz uma descrição adequada e, com semelhante força, inadequada da vida de um juiz. Trata-se de uma cilada difícil de escapar.

Várias respostas se apresentam quando se questiona a tarefa fundamental do juiz. Umas das tarefas mais angustiantes de um magistrado é a atribuição de avaliar o comportamento de seus semelhantes. Ora, para exercer essa tarefa parece razoável (até mesmo esperado pelos jurisdicionados), que o julgador se coloque em posição diferente àquele que é julgado. Neste sentido:

No meio jurídico existe um jargão bastante conhecido que diz: "a magistratura é um sacerdócio". Pode-se dizer que a comparação entre os dois ofícios se deve, principalmente, à extremada dedicação profissional exigida desses sujeitos e à severa cobrança social de observância de normas de conduta a que são submetidos, uma vez que tanto os juízes como os religiosos servem como referência de retidão moral e comportamental para toda a coletividade. Curiosamente, ao olhar o tema mais de perto, percebe-se que as semelhanças entre juízes e sacerdotes são ainda mais profundas. Ambos têm permissão social para um contato privilegiado com o divino, atuando como "procuradores de Deus na Terra", na medida em que fazem o que só a Ele é permitido: julgar, condenar e também redimir o pecador de sua culpa. (CARRARO; PENSO, 2010, p. 15).

De qualquer forma, para ser bem-aceito na tarefa de julgar, o juiz precisa ser visto como uma figura superior. Poucas pessoas aceitam ter seu comportamento avaliado por alguém que não ostenta autoridade para tanto.

Nosso sistema não dá essa opção aos jurisdicionados (ou clientes, em linguagem mais moderna), pois o Estado atua com mecanismos necessários para impor a decisão da pessoa que ocupa a função, ainda que aparentemente não ostente a autoridade reconhecida. Exemplo disso é a força das decisões a uma pessoa racista prolatada por quem se acredita ser inferior. Mesmo que a pessoa não aceite a decisão, desprezando o prolator da decisão, o Estado impõe a medida aplicada.

Assim aceito, a tarefa exige que o julgador ostente e se coloque em posição de superioridade. E tal ostentação tem justificativa histórica.

Em culturas mais antigas, a tarefa de julgar era recebida diretamente de Deus e, nesse contexto, nenhuma pessoa ou comunidade tinha força suficiente para resistir à decisão. Com a chegada do Iluminismo, essa condição foi afastada. A partir de então, o juiz é pessoa comum, reconhecido por sua inteligência e sensibilidade que o capacita a captar o sentimento da sociedade, julgando em conformidade com o que dele se espera. Nesta função, o homem escolhido deve perceber os efeitos da sua decisão a longo prazo, não se perdendo em querelas temporárias, sob pena de causar insegurança mudando de posição, tal qual uma biruta que gira em conformidade com o sentido do vento.

O juiz, então, é apenas um homem, com qualidades especiais que o distingue dos demais, distinção essa que o faz diferente. Os clientes assim o exigem.

Ainda assim, permanece no consciente coletivo aquele sentimento de que o ato de julgar é divino, superior. Sentir-se divino é uma armadilha da qual não se escapa sem alguma habilidade. No meio jurídico, notadamente entre advogados, é bastante comum a utilização do termo juizite, atribuído normalmente aos juízes mais novatos que se comportam como seres superiores ao ponto de não se permitir conhecer das angústias que lhe são apresentadas. O juiz acometido por este erro acredita que o problema dos outros é coisa pequena e assim deve ser tratado, sequer merecendo a sua atenção. 
“A propósito, também é importante lembrar o termo juizite, normalmente utilizado para os magistrados em início de carreira que modificam seu comportamento, portando-se não mais como pessoa comum, mas na condição especial que se espera de um ser diferente, especial" (SANTOS, 2009, p. 89).

O juiz desavisado se percebe superior e a arapuca se concretiza. Essa armadilha advém da falta de percepção que consiste em separar a função que se ocupa em determinados momentos do dia e a figura do homem, que está presente perenemente.

O juiz é infalível, o homem não. Saber o momento de despir-se da beca e passar a ser pai, marido, filho, trabalhador e várias outras funções que o homem ocupa no decorrer do dia é o divisor de águas. Esse aspecto é ressaltado por Prado, quando avalia o que denomina aspectos sombrios da personalidade do juiz:

Essa situação significa que o juiz torna-se tão-somente juiz, esquecendo-se que tem como possibilidade um réu dentro de si. $\mathrm{O}$ ego identifica-se com a persona, fato muito lesivo, porque redunda na ofuscação da consciência por um conteúdo inconsciente. $\mathrm{O}$ magistrado tenta ser divino, sem máculas, incidindo, às vezes na hybris (descomedimento) de se considerar a própria Justiça encarnada (porque só os deuses julgam os mortais). Esse fenômeno chama-se inflação da persona, que ocorre quando os magistrados de tal forma se identificam com as roupas talares, que não mais conseguem desvesti-las nas relações familiares ou sociais. Inflação da persona causa fragilidade ou rigidez da psique. (PRADO, 2003, p. 45).

Para a sanidade de quem exerce essa tarefa, saber dividir o tempo e "tirar a toga" em certo momento do dia, é essencial. A confusão na figura do personagem/juiz e na pessoa que exerce o cargo causa estragos graves na vida do homem. Calamandrei afirma existir todo um sistema para o juiz se sentir atraído a ver-se infalível.

Grave defeito num juiz é a soberba; mas talvez seja uma doença profissional. Não sei se há juízes que, quando julgam, se creem infalíveis; mas, se há, é justo reconhecer que nosso rito judiciário e, além dele, nosso costume forense parecem feitos de propósito para induzir o juiz à tentação do orgulho. (CALAMANDREI, 1997, p. 62).

Entretanto, conforme alertam Carraro e Penso, a armadilha é poderosa:

Trazendo os conceitos de Jung para o presente trabalho, podemos afirmar que, assim como qualquer ser humano, o juiz tem em seu inconsciente pessoal os elementos do inconsciente coletivo e também a imagem arquetípica do que seria o "juiz universal". Com efeito, as informações sobre o aspecto divino do papel do julgador e o modelo de comportamento irrepreensível que seria de um magistrado típico são pertencentes a toda a coletividade, não variando de cultura para cultura, e, portanto, repassados de forma inconsciente para as gerações seguintes. (CARRARO; PENSO, 2010, p. 10).

A falta de atenção na busca de diferenciar o homem e o profissional pode resultar no comprometimento de sua relação familiar ou mesmo com sua saúde, com grave reflexos na pessoa e até mesmo no profissional.

Santos apontou a potencialidade do adoecimento e a necessidade de acompanhamento profissional, bem como empreendeu esforços para evidenciar que o Magistrado é uma pessoa comum, escolhida para exercer a função das mais relevantes no Estado.

Ao buscar obedecer aos padrões idealizados, os juízes deixam de lado seus próprios desejos, em razão da pressão social ou até mesmo pelo peso do cargo. O resultado disto acaba sendo a depressão, ou outro adoecimento emocional que possa advir deste sofrimento. Importante esclarecer que não é o cargo em si que traz sofrimento, mas o 
estilo de vida que se obrigado a levar exercer o cargo. Este estilo está ligado ao próprio "eu" do sujeito, a sua personalidade. (SANTOS, 2009, p. 118).

Demora-se um pouco para poder separar a função do homem que a exerce. Hoje, já é possível admitir a presunção de ter conseguido diferenciar. Todavia, existe um preço a ser pago. Constata-se consequências de ter vida além da Magistratura, pois ao mesmo tempo que se deseja um juiz/homem, também se espera um juiz/divino.

A sociedade quer o juiz durante as 24 horas do dia desejando que não exista o homem. Desta forma, não pode o homem aparecer. Não pode se comportar como qualquer outro profissional, como, por exemplo, envolver-se em querelas com outras pessoas, não pode ingerir bebida alcoólica, não pode se separar da esposa, não pode se envolver em acidente de trânsito. Resumindo, o homem, quando investido na figura do juiz, não pode errar.

Quando o profissional decide ter uma vida além da Magistratura, comportando-se e agindo com qualquer outra pessoa, usando de sua faculdade de, na vida privada, cometer equívocos, deve estar preparado para ser julgado com maior rigidez. A crítica é muito mais ácida.

É importante ter esta percepção, sob pena de reagir de forma indevida. Às vezes confrontando inadequadamente o crítico, outras, optando por mudar seu comportamento tornando-se uma pessoa a levar uma vida reclusa. Em ambas as situações, o desequilíbrio é a marca resultante. A aceitação da crítica e a opção de continuar a ter uma vida comum é uma medida complexa, mas mais adequada.

\subsection{A função do juiz criminal no sistema judicial brasileiro}

Para os fins deste estudo, a avaliação fica mais centrada no profissional que exerce a jurisdição criminal, mas vários apontamentos também podem ser aplicados para outras áreas da jurisdição.

No processo criminal se decide um dos bens mais importantes do cidadão: a liberdade. A retirada desse bem traz outras graves consequências, tanto no plano pessoal, familiar, patrimonial, sentimental. Afastar uma pessoa de sua família, tornando os filhos carentes da figura paterna (ou materna) é uma agressão imensa, tanto do ponto de vista da formação da personalidade quando na dificuldade da subsistência da prole. Não bastasse isso, o encarceramento também causa grave lesão no Estado, que além de perder uma força de trabalho, expende grande energia para a manutenção do sistema prisional.

Também chama a atenção a circunstância de o processo ser um mundo à parte do real, diferente do concreto. Em outras palavras, a reconstrução que se busca fazer do fato acontecido nem sempre é reflexo da realidade.

Existe um conhecido brocardo jurídico advindo do latim "quod non est in actis non est in mundo" apontando "o que não está nos autos não está no mundo".

As pessoas leigas ou com conhecimento curto em direito, notadamente em matéria criminal, não conseguem entender a possibilidade de o processo refletir de forma diferente o que aconteceu no mundo concreto.

O mundo do processo consiste em tentar reconstituir o que aconteceu no mundo real. Por deficiência na instrução, tanto material quanto humano, nem sempre essa tarefa é desempenhada de forma satisfatória. Neste caso, quando se compara com o esperado, a resposta dada no processo pode ser inadequada e a prestação entregue pode ser defeituosa, com consequências nefastas.

O julgador tem ciência desta possibilidade e deve ocupar-se dela, para fins de evitar um dano maior do que naturalmente decorre do exercício do seu mister. 
Qualquer estudante de direito costuma enxergar o juiz como uma pessoa genial. Um profissional que poderia satisfazer todos os anseios da sociedade. Fazer justiça, tarefa que se atribui ao Poder Judiciário e, na ponta desta espada, ao juiz, significava pacificar, tornar todo mundo feliz.

Quando o sonho de ser magistrado é alcançado vem a realidade: pacificar o mundo é um objetivo impossível de ser alcançado para um homem. Tornar feliz a humanidade é um objetivo celestial, acima das pretensões individuais.

Logo no ingresso na carreira da Magistratura, é realizado um curso de preparação à Magistratura e nesta oportunidade vem o primeiro choque de realidade. Luiz Alberto Warat foi jurista argentino, radicado no Brasil que se notabilizou, dentre outras coisas, pela forma provocativa que abordava temas polêmicos, no atual sistema, a função do juiz é manter a injustiça. Sustentava o notável jurista que o juiz existia para manter o sistema, impedindo ou dificultando a mudança. Concluindo que o sistema era injusto com os mais necessitados, em última análise, o juiz deveria manter essa injustiça.

Pelo contexto do trabalho apresentado, essa também foi a ideia percebida por Sena, quando sustentou:

\begin{abstract}
A figura do juiz, concebida modernamente como mero aplicador da norma, não pode subsistir. Antes se pensava que a neutralidade do julgador é que garantiria o resultado justo. Isso porque a lei, confeccionada pelo "legislador racional", seria aplicada a todos indistintamente. Hoje, percebe-se que a distorção dos ideais constitucionais e a injustiça são provocadas, justamente, pelo magistrado que permanece em seu tablado, acima das partes, e não desce à realidade para assumir seu papel de agente político e transformador. No contexto de um Estado ineficaz, que não garante sequer a concretização dos direitos fundamentais, a neutralidade do magistrado, antes sinônimo de Justiça, agora constitui hermetismo judicial, cuja permanência implica a manutenção do status quo e, portanto, a perpetuação de desigualdades. (SENA, 2010, p. 11-12).
\end{abstract}

É forçoso reconhecer que existe uma forte lógica no pensamento do doutrinador. Uma das funções primordiais da justiça é a pacificação social. É comum acreditar que estamos em época de paz e este equilíbrio acaba sendo comprometido com o surgimento de novos posicionamentos, novas ideias.

Em outras palavras, os conflitos somente acontecem quando alguém tenta afrontar uma posição já posta. Neste momento, surge o juiz para restabelecer o estado anterior.

Da ideia (e sonho) inicial de ocupar a função e fazer feliz o jurisdicionado, a realidade apontava o oposto: manter a injustiça, a infelicidade. $\mathrm{O}$ sonho precisa se adequar à realidade. $\mathrm{A}$ tarefa do juiz não é mais tornar feliz a sociedade, mas interferir positivamente na vida das pessoas que se apresentam como clientes. Mudar no micro, tentar tornar feliz uma pessoa de cada vez.

O reconhecimento da dignidade da pessoa humana, com o enfoque mais específico da sustentabilidade social, permite ao juiz se localizar no mundo e buscar a realização dessa mudança. Nalini assevera que se deve exigir mais do juiz do que mero conhecimento técnico e aplicação pura da lei em busca da pacificação social.

Em um Brasil campeão das iniquidades, em que a desigualdade ainda é a regra, um País de paradoxos gritantes, o Judiciário poderia concretizar as promessas do constituinte. Mas se ele for integrado por pessoas tecnicamente capazes, mas com descompasso na formação ética, de nada adiantará uma resposta correta à luz da lei, se ela não gerar a pacificação. (NALINI, 2014, p. 2). 
É exatamente neste ponto que se identifica a tarefa do magistrado, notadamente aquele que exerce a Magistratura criminal: o juiz é a última esperança do indivíduo prestes a perder boa parcela de sua condição como cidadão.

\section{A ASPEREZA DO PROCESSO CRIMINAL}

Fazendo uma digressão sobre o sistema jurídico criminal é importante relembrar que, até o momento em que uma pessoa é trazida na presença do juiz, o Estado não lhe dá nenhuma oportunidade de fazer prova em seu favor.

No nosso sistema, o processo somente se inicia quando o fato é apresentado ao Estado/juiz para avaliação. A partir de então, o cidadão passa a ostentar a condição de acusado, merecendo, somente a partir deste momento, todas garantias previstas na Constituição, notadamente o contraditório e ampla defesa.

$\mathrm{Na}$ parcela que antecede a chegada do suspeito à frente do juiz, o sistema jurídico brasileiro obedece a um modelo nefasto, pois o procedimento é inquisitorial, de lembrança triste na história da humanidade, quando a Igreja Católica através da Santa Inquisição - Tribunal Eclesiástico investigava e punia quem fosse contrário à doutrina da igreja, sem dar qualquer chance de defesa. Costumeiramente o procedimento levava à morte. $\mathrm{O}$ que se decidia era se a morte iria ou não ser precedida pela tortura.

Em apertada síntese, quando uma pessoa chega na frente do juiz, o Estado (e porque não dizer toda a comunidade) está contra o cidadão. Ele foi preso ou considerado suspeito pela polícia, o delegado encontrou informações suficientes para indiciá-lo, o promotor de justiça concluiu que a pessoa deve ser processada. Chega agora o juiz que, se não perceber a gravidade da situação, também age como o Estado vinha agindo até então e trata o cidadão como criminoso.

Urge destacar que desde que lhe foi imputada a autoria de um crime, o cidadão fica dependente da seriedade das pessoas que o trouxeram na frente do juiz.

Não se pode ser preconceituoso e imaginar que algum desses profissionais agiria de máfé, mas a possibilidade existe. Ao largo disso, também se constata situações em que esses profissionais, baseado nos conhecimentos e (pre)conceitos que possuem, realmente acreditam que o indivíduo deva ser responsabilizado, mesmo sem provas suficientes para o convencimento.

Se o juiz não se atentar que é a última esperança do indivíduo contra o Estado, certamente perpetuará a injusta alertada pelo Prof. Dr. Luiz Alberto Warat. A advertência é pertinente, pois existe uma pressão social imensa para responsabilizar a pessoa, independentemente de ter sido ou não responsável pelo fato praticado.

Neste ponto, é importante salientar, respeitando opiniões em contrário, que o magistrado não pode se ver como instrumento no combate à criminalidade, sob pena de comprometer a sua isenção.

O processo criminal deve buscar a responsabilização daquelas pessoas que praticaram um fato criminoso. Da responsabilização é possível extrair que fica a mensagem para as demais pessoas que não cometam crimes, caracterizando o princípio da prevenção geral. Esta circunstância não pode confundir o julgador.

Se enxergar sua atuação como instrumento no combate à criminalidade emerge forte tendência de atuar como justiceiro, apenas confirmando a irregularidade advinda da fase inquisitorial.

A maioria dos acadêmicos de Direito, como reflexo da população em geral, tem propensão para reagir de forma negativa a uma acusação, querendo a responsabilização mesmo sem ter conhecimento adequado sobre o fato acontecido e as provas existentes. 
Essa percepção também é possível atribuir à sociedade, notadamente àqueles que tem conhecimento jurídico, mas não tem proximidade com a causa, juízes inclusive.

Exclusivamente neste contexto, a sociedade prestigia o policial que prende e o promotor de justiça que busca a responsabilização. O juiz normalmente é visto como a pessoa que solta o criminoso.

Constatando a fraqueza do Estado em lhe dar segurança, parcela considerável da sociedade busca, então, um juiz vingador, saneador de suas angústias. Um juiz que os torne felizes confirmando a responsabilização que já veio antes, um julgamento já feito pela força da opinião de pessoas que não presenciaram a prática do crime, não conhecem os envolvidos e nem se confrontaram com a realidade dos autos, mas se sentem autorizados a julgar.

Vou deixar de lado a possibilidade patológica de algum agente do Estado, por vontade própria, ter trabalhado para fraudar o sistema e implicar com uma pessoa inocente, comprometendo a atuação dos demais. Essa possibilidade existe, mas trata-se de uma doença do sistema que merece ser avaliada em outro trabalho, com objetivo específico.

\section{ALGUNS DIREITOS DO CIDAdÃO PROCESSADO OU CONDENADO}

Trata-se de uma proposta nada inovadora, mas apenas uma forma diferente de enxergar a pessoa que foi acusada de ter praticado o crime e, nessa esteira, concretamente impor ao Estado o cumprimento de sua tarefa.

Contagiado pelo espírito da sustentabilidade social, o magistrado criminal deve atuar sempre em busca de uma solução que se traduza em uma sociedade equilibrada, inclusiva e esforçando-se para rejeitar qualquer forma de discriminação em face da pessoa processada.

Nesta tarefa, deve o juiz manter distância do que até então se disse sobre o caso em avaliação, preferencialmente entrando no processo sem conhecer a discussão. Neste cenário, a possibilidade de manter a neutralidade é bem maior do que aquele que já tem opinião formada ou conhecimento prévio sobre a celeuma.

Neste formato proposto, o juiz outorga às partes, acusação e defesa, que façam o seu serviço, reconstruindo os fatos em busca de levar o julgador ao cenário do crime. O que se permite ao juiz, em relação ao que já foi feito, é avistar-se com as perícias técnicas, isso depois de ouvir as informações que a prova oral for apresentada.

Numa sociedade globalizada, onde todas as notícias são imediatamente compartilhadas com todos, não é tarefa fácil para um juiz manter-se neutro. Mas com aquela diferenciação de papéis, anteriormente recomendada, o juiz despe-se da condição de cidadão e, desde o momento que veste a toda, transforma-se.

É um exercício diário. Ser ouvido e julgado por um juiz imparcial é a principal reclamação dos acusados. É direito do agente que o julgador busque avaliar as razões do próprio acusado ao resolver delinquir.

Para julgar de forma imparcial, o juiz deve utilizar-se do que Hannah Arendt denomina "mentalidade alargada" ou "alargamento do espírito", que considera a possibilidade de, na sua própria decisão, vislumbrar a forma de pensar dos outros, comparando o próprio padrão com outros padrões possíveis. Este comportamento permite avaliar a conduta não mais do ponto de vista do julgador, mas do que supõe provável a forma de pensar da pessoa submetida à Jurisdição. "Isto se faz comparando-se nosso juízo com o juízo possível dos outros, e não com o real, e colocando-nos no lugar de qualquer outro homem, abstraindo-nos das limitações que contingentemente se juntam a nosso próprio juízo" (ARENDT, 2000, p. 379).

Ao largo disso, não basta ao juiz fazer o mero enquadramento do fato com o comportamento do agente. O desafio consiste em ir além, vislumbrando o resultado de sua atuação para além do processo, buscando a pacificação social com a necessária mudança no estado anterior, sem desconsiderar o principal ator neste processo: o acusado. 
Pode parecer contraditório falar em "tornar feliz uma pessoa" na esfera criminal, mas é cabível buscar o que aparenta ser improvável. Tornar feliz um acusado, não significa necessariamente absolvê-lo. Além de proporcionar-lhe todas as condições para que consiga afastar de si a imputação, sem preconceitos, deve o juiz ir além.

Mais do que qualquer outro profissional, o juiz deve evidenciar sua condição de derradeira esperança do acusado.

Sempre que uma pessoa for trazida à sua presença como acusado, por mais desprezível que seja o crime praticado, o acusado merece um tratamento respeitoso.

Toda e qualquer pessoa merece a sensação de que existe a possibilidade de ser absolvido, merece ser chamado de "senhor" por todos, tem direito de contar com a atenção do juiz quando traz sua versão dos fatos. Sempre que possível, deve ser perguntado sobre a sua história de vida, falar sobre seus filhos, seus pais, suas angústias e esperanças. Na sentença, para fins de personalizar, deve o juiz utilizar o nome próprio do cidadão, evitando a grafia "acusado".

Que, apesar do erro cometido e que merece ser responsabilizado, tem seu valor e importância na construção de uma sociedade mais feliz.

Uma das tarefas mais desafiadoras para o juiz é despertar no acusado uma noção de pertencimento. Demonstrar que o indivíduo tem importância para a sociedade, destacando e perguntando ao acusado como está o cumprimento do seu papel como pai, filho, marido, trabalhador.

Outro esforço do juiz se presta a permitir que o acusado tenha pleno conhecimento do que está acontecendo, do que representa o processo. Neste aspecto, o uso de uma linguagem coloquial e, mais importante ainda, usar palavras próprias do meio em que vive o acusado, inclusive gírias. Para tanto, deve o juiz exigir de si mesmo uma constante atualização, sempre aprendendo com os próprios acusados. Esta tarefa, aparentemente tão singela, se destina a reforçar o pertencimento.

Mal realizada essa tarefa, reproduz a situação noticiada por Kafka (2011), quando Josef K., mesmo sem nada ter praticado de irregular e acreditando que sua inocência seria revelada tão logo pudesse contar se viu processado, julgado e a pena executada, sem sequer entender qual foi o crime que cometera.

\section{CONSIDERAÇÕES FINAIS}

Uma das consequências que se destacam com a condenação é a perda importante aspecto da cidadania, consistente no direito de interferir nos destinos da sociedade, já que perde o direito de votar e ser votado.

Não apenas por isso, mas também por esta consequência, é imprescindível que o magistrado criminal deva se enxergar como a derradeira fronteira do cidadão em confronto com o Estado, reconhecendo a possibilidade concreta de aquele fato não ter sido por praticado pela pessoa escolhida pelo Estado ou mesmo ter sido praticado por aquela pessoa, mas de forma diferente da anunciada na denúncia.

Essa forma de enxergar o processo impõe ao Estado/acusação a tarefa de comprovar tudo o que até então se afirmava. Do contrário, se o juiz receber o acusado com preconceito, ele já vem prejudicado, cabendo a ele mesmo a tarefa de desconstituir o que já se produziu, perpetuando o sistema inquisitorial.

Antes que se traga alguma maledicência, não desconhecemos que nosso sistema é sustentado pelo princípio da presunção da inocência previsto pelo art. $5^{\circ}$, LVII da Constituição de 1988, que enuncia: "ninguém será considerado culpado até trânsito em julgado de sentença penal condenatória”. 
Desta forma, parece desnecessário e até inútil o presente alerta. Mas não é. O sistema foi construído com base na avaliação do fato. O objetivo do processo é fazer uma reconstrução histórica levando o juiz ao local e momento em que o fato foi praticado. Olhando o fato externamente, o juiz pode avaliar fatos, pessoas e imputar responsabilidades com a necessária isenção.

Portanto, em primeiro momento, o que se deve analisar é o fato praticado. Todavia, existe uma forte tendência em enxergar a pessoa do acusado antes mesmo de se debruçar sobre o fato trazido a avaliação.

Nesse particular emerge a figura do direito penal do autor, agora com nova roupagem, denominado direito penal do inimigo, essa última teoria criada pelo doutrinador alemão Gunther Jakobs. Neste contexto Silva destaca que:

O ilustre professor penalista alemão Günther Jakobs, após o milênio, apresenta à sua tese denominada Direito Penal do Inimigo, que nada mais é que o direito punitivista que retira as garantias fundamentais inerentes àqueles classificados como inimigos pelo Estado, que age de forma autoritarista. De acordo com o autor a reprovação se dá mediante o caráter do agente e não pelo fato criminoso que praticou, configurandose um direito penal do autor, que foi tão criticado na $2^{\circ}$ Guerra Mundial quando foi usado por Adolf Hitler para justificar o nazismo alemão. (SILVA, 2012, p. 2).

Em apertada síntese, no direito penal do autor o que se prestigia (negativamente) é a pessoa acusada da prática do fato, deixando a avaliação do próprio fato em segundo plano. $\mathrm{O}$ acontecimento também é importante, mas a personalidade da pessoa que o praticou deve ser esmiuçada em primeiro plano para fins de determinar a imputação e a pena correspondente.

\section{REFERÊNCIAS}

ARENDT, Hannah. A vida do espírito. Rio de Janeiro: Relume-Dumará, 2000.

CALAMANDREI, Piero. Eles, os juízes, vistos por um advogado. 3. ed. São Paulo: Martins Fontes, 1997.

CARRARO, Mariana Pereira de Queiroz; PENSO, Maria Aparecida. Juízes de batina: reflexões sobre a relação entre a magistratura e o divino na formação do arquétipo do juiz. 2010. Trabalho de Conclusão de Curso (Especialização em Psicologia Jurídica). Universidade Católica de Brasília. Disponível em: http://repositorio.ucb.br/jspui/bitstream/10869/4527/1/Mariana\%20Pereira\%20 de\%20Queiroz\%20Carraro.pdf. Acesso em: 14 mai. 2021.

KAFKA, Franz. O Processo. 5. Ed. São Paulo: Martin Claret, 2011.

GARCIA, Denise Schmitt Siqueira. O caminho para a Sustentabilidade. In: GARCIA, Denise Schmitt Siqueira (org.). Debates Sustentáveis: análise multidimensional e governança ambiental. Itajaí: UNIVALI, 2015.

GARCIA, Denise Schmitt Siqueira; GARCIA, Heloise Siqueira. Mínimo existencial ecológico: a intrínseca relação entre a dignidade da pessoa humana e a qualidade ambiental. Empório do Direito, 2015. Disponível em: http://emporiododireito.com.br/minimo-existencial-ecologico-a-intrinseca-relacao-entre-a- 
dignidade-da-pessoa-humana-e-a-qualidade-ambiental-por-denise-schmitt-siqueira-garcia-eheloise-siqueira-garcial. Acesso em: 14 mai. 2021.

NALINI, José Roberto. O juiz ideal e o juiz possível. Rio de Janeiro, Justiça e Cidadania, 2014. Disponível em: http://www.editorajc.com.br/2014/10/o-juiz-ideal-e-ojuiz-possivel/. Acesso em: 14 mai. 2021.

MAGALHÃES, Leslei Lester dos Anjos. O principio da dignidade da pessoa humana e o direito à vida. São Paulo: Saraiva, 2012.

PRADO, Lídia Reis de Almeida. O juiz e a Emoção. Campinas: Millennium Editora, 2003.

REAL FERRER, Gabriel. Calidad de vida, medio ambiente, sostenibilidad y ciudadanía ¿Construimos juntos el futuro? Revista Eletrônica Novos Estudos Jurídicos, Itajaí, v. 17, n. 3, p. 310-326, dezembro de 2012. Disponível em: http://siaiweb06.univali.br/seer/index.php/nej/article/view/4202/2413. Acesso em: 14 mai. 2021.

SANTOS, Franklin Vieira dos. A Magistratura e o adoecimento no trabalho: aspectos jurídicos e psicológicos. Dissertação (Mestrado Profissional em Poder Judiciário). Fundação Getúlio Vargas, Porto Velho-RO, 2009. Disponível em:

http://www.dominiopublico.gov.br/download/teste/arqs/cp152878.pdf. Acesso em: 14 mai. 2021.

SENA, Jaqueline Santa Brígida. O dogma da neutralidade na prestação jurisdicional: uma abordagem jusfilosófica a partir do pensamento de Luiz Alberto Warat. Dissertação (Mestrado em Direito). Universidade de São Paulo, São Paulo, 2010. Disponível em:

file://C:/Users/101156/Downloads/versao_completa_Jaqueline_Sena.pdf. Acesso em: 14 mai. 2021.

SILVA, Flávia Regina Oliveira da. Direito penal do inimigo e sua incompatibilidade com o estado democrático brasileiro. In: Âmbito Jurídico, Rio Grande, XV, n. 99, abr. 2012. Disponível em:

http://www.ambitojuridico.com.br/site/?n_link=revista_artigos $\% 20$ leitura\&artigo_id=11424. Acesso em: 14 mai. 2021. 